\title{
Management of Myelotoxicity (Aplasia) and Infectious Complications
}

\author{
Marion Subklewe and Reuben Benjamin
}

Haematologic toxicity is the most common adverse event after CAR-T cell therapy, with a cumulative 1-year incidence of 58\% (CTCAE grade $\geq 3$ ) in the real-world setting (Wudhikarn et al., Blood Advances 2020). It is characterized by a biphasic temporal course and is often prolonged (Fried et al., Bone Marrow Transplant 2019, Rejeski et al., Blood et al. 2021a, b, Fig. 29.1). In a report of Axi-Cel-treated patients, only $30 \%$ demonstrated a neutrophil count $>1 \times 10^{9} / \mathrm{L}$ and $50 \%$ showed a platelet count $>50 \times 10^{9} / \mathrm{L}$ at 30 days following CAR-T cell treatment (Jain et al., Blood Advances 2020). In a long-term follow-up study of patients with ongoing CR and an absence of MDS, $16 \%$ of patients experienced prolonged significant cytopenias that lasted up to 22 months after CAR-T cell treatment (Cordeiro et al., Biol Blood Marrow Transplant 2020). These findings highlight that cytopenia can present long after lymphodepletion and the resolution of acute CRS. Risk factors include severe CRS/ICANS, cytopenia prior to initiation of lymphodepleting chemotherapy, and prior allogeneic stem cell transplantation (Jain et al., Blood Advances 2020, Fried et al., BMT, 2019). Importantly, cytopenia predisposes patients to severe infectious complications, which are the most frequent cause of non-relapse mortality (Nastoupil et al., JCO 2020).

The use of growth factors to manage early cytopenias after CAR-T cell therapy remains controversial. Cytokine profiles and mouse xenograft models have implicated GM-CSF in the pathogenesis of CRS and neuroinflammation (Sterner et al., Blood 2019). Accordingly, current recommendations discourage the use of GM-CSF and to initiate G-CSF only after resolution of CRS and/or ICANS (Yakoub-Agha et al., Haematologica 2020). However, in a report by Galli et al., prophylactic

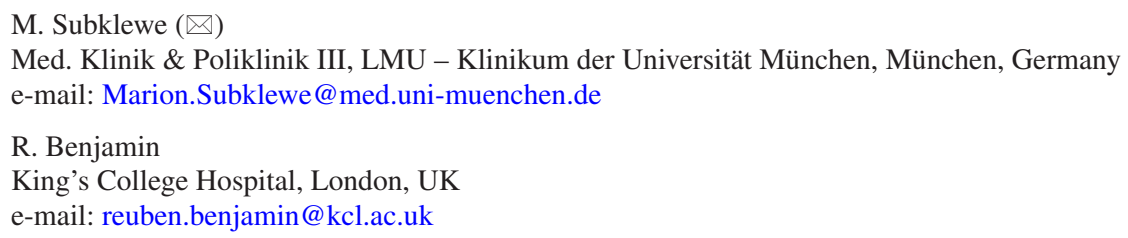




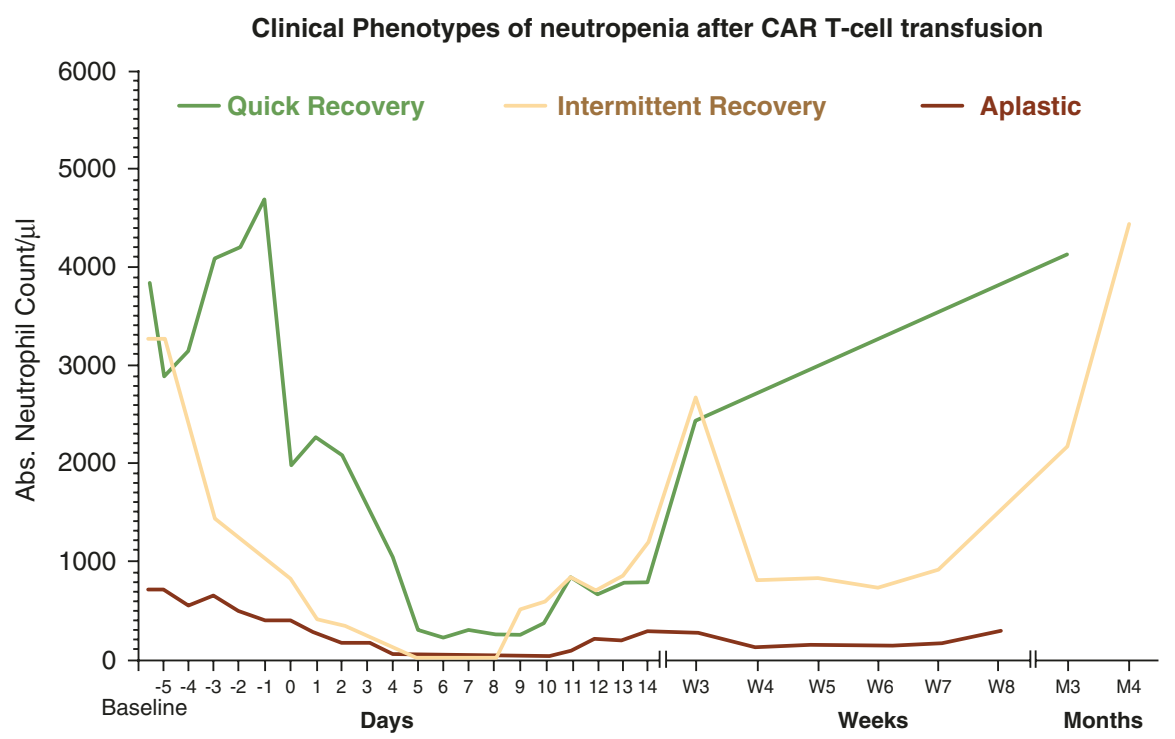

Fig. 29.1 Clinical Phenotypes of neutropenia (adapted from Rejeski et al., Blood 2021a, b)

G-CSF was used safely in 42 patients with grade 4 neutropenia on day 5 after CAR-T cell infusion, with no increased risk of CRS or ICANS and no negative impact on disease outcomes (Galli et al., Bone Marrow Transplantation 2020). Further studies are needed to identify patients at high risk for prolonged neutropenia and with an increased risk of infection that will benefit from early G-CSF initiation. The diagnostic workup for patients with prolonged cytopenia unresponsive to G-CSF should include screening for haematinic deficiency, viral infections (e.g., CMV, EBV, Hepatitis B/C, Parvovirus B19), concomitant myelosuppressive drugs (e.g., co-trimoxazole), secondary haemophagocytic lymphohistiocytosis, and the presence of disease in the bone marrow. In the event of severe bone marrow aplasia unresponsive to G-CSF, autologous or allogeneic stem cell rescue may be considered where possible (Rejeski et al., BMC ID 2021a, b, Godel et al., Haemasphere 2021). Other options include anti-inflammatory therapy (e.g., dexamethasone, antiIL-6 blocking therapy) and thrombopoietin receptor agonists (e.g., eltrombopag) (Fig. 29.2).

Infections are another significant complication of CAR-T therapy as a result of prolonged neutropenia, long-term CD4 T cell lymphopenia, or B-cell aplasia (Hill and Seo et al., Blood 2020a, b). Other risk factors associated with infections include higher CRS grade and use of immunosuppressive agents, such as steroids, tocilizumab, and anakinra. The majority of infections occur early within the first 28 days, with bacterial infections being the most common, followed by viral and fungal infections. Late infections, especially with respiratory viruses, are also seen up to 90 days post CAR-T therapy (Cordeiro et al., BBMT 2020). Invasive fungal 


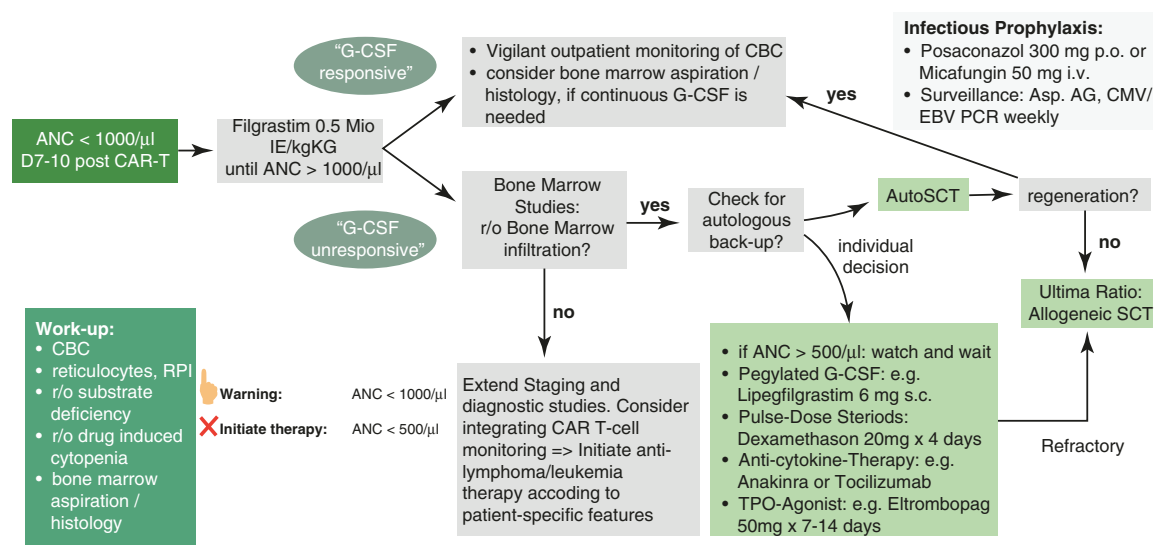

Rejeski et al, 2021, Godel et al, 2021 Hill and Seo et al, Blood Advances 2020

Fig. 29.2 Treatment algorithm for CD19 CAR-T cell-associated myelotoxicity

infections, both yeasts and moulds, have been reported in 1-15\% of CAR-T-treated patients.

The use of antiviral, antifungal, and anti-pneumocystis (PCP) prophylaxis to reduce the risk of infections post-CAR-T cell therapy is recommended; however, there is no consensus on the optimal choice and duration of prophylaxis. Patients typically receive acyclovir or valacyclovir, yeast or mould-active antifungal prophylaxis, and co-trimoxazole to prevent PCP. Patients considered "high risk" for mould infections based on pre-infusion neutropenia, history of mould infection within 6 months, prior allo-SCT or underlying diagnosis of acute leukaemia as well as those who have had post-infusion grade $\geq 3 \mathrm{CRS} / \mathrm{ICANS}$ or prolonged treatment with steroids or other immunosuppressants should be offered mould-active prophylaxis. In the absence of high-risk factors, yeast-active prophylaxis may be sufficient, with pre-emptive monitoring for moulds recommended (Garner et al., J Fungi 2021). Antifungal prophylaxis is generally continued until recovery of the neutrophil count and cessation of immunosuppressants. PCP prophylaxis is typically given for 6 months or until the CD4 T cell count is $>200$ cells/ $\mu 1$. Monthly intravenous immunoglobulins may be considered when there is persistent severe hypogammaglobulinaemia and a history of recurrent infections. Treatment of suspected/ confirmed infections post CAR-T therapy should follow Institutional guidelines and is generally similar to the management of infections after stem cell transplantation. The efficacy of vaccination following administration of CD19- or BCMA-targeted CAR-T cells remains unknown, but patients do need to be considered for vaccination at 6 months post-CAR-T therapy and guided by post-vaccine antibody titres (Hill et al., Blood 2020a, b). Effective strategies to prevent and manage infectious complications following CAR-T cell infusion are crucial in improving the outcomes of this promising therapy. 


\section{Key Points}

- Haematological toxicity is the most common adverse event after CD19specific CAR-T cell therapy and can predispose patients to severe infectious complications.

- Administering prophylactic $G-C S F$ from day 5 in neutropenic patients does not increase the incidence of severe CRS/ICANS and is safe in preserving CAR-T antilymphoma activity. Evidence level III-B.

- Post-CART immunosuppression is multifactorial (e.g., neutropenia, lymphopenia, steroid use, B-cell aplasia, and hypogammaglobulinaemia), and infections significantly contribute to non-relapse mortality.

- Anti-infective prophylaxis should follow institutional guidelines based on the patient-specific risk factors.

\section{References}

Cordeiro A, et al. Late events after treatment with CD19-targeted chimeric antigen receptor modified T cells. Biol Blood Marrow Transplant. 2020;26(1):26-33.

Fried S, et al. Early and late hematologic toxicity following CD19 CAR-T cells. Bone Marrow Transplant. 2019;54(10):1643-50.

Galli E, Allain V, Blasi R, Bernad S, Vercellino L, Morin F, Moatti H, Caillat-Zucman S, Chevret S, Thieblemont C. G-CSF does not worsen toxicities and efficacy of CAR-T cells in refractory/ relapsed B-cell lymphoma. Bone Marrow Transplant. 2020;55:2347-9.

Goedel P, Sieg N, Heger JM, Kutsch N, Herling C, Bärmann B-N, Scheid C, Borchmann HU. Hematologic rescue of CAR-T cell mediated prolonged pancytopenia using autologous peripheral blood hematopoietic stem cells in a lymphoma patient. Hema. 2021;5(3):e545.

Hill JA, Seo SK. How I prevent infections in patients receiving CD19-targeted chimeric antigen receptor T cells for B-cell malignancies. Blood. 2020b;136(8):925-35.

Hill JH, Seo S. How I prevent infections in patients receiving CD19-targeted chimeric antigen receptor T cells for B-cell malignancies. Blood. 2020a;136(8):925-35.

Jain $\mathrm{T}$, et al. Hematopoietic recovery in patients receiving chimeric antigen receptor T-cell therapy for hematologic malignancies. Blood Adv. 2020;4(15):3776-87.

Nastoupil LJ, Jain MD, Feng L, et al. Standard-of-care Axicabtagene Ciloleucel for relapsed or refractory large B-cell lymphoma: results from the US lymphoma CAR-T consortium. J Clin Oncol. 2020;38(27):3119-28.

Rejeski, $\mathrm{K}$ et al, CAR-HEMATOTOX: A model for CAR-T cell related hematological toxicity in relapsed/refractory large B-cell lymphoma. Blood 2021a Jun 24; online ahead of print.

Rejeski K, Kunz WG, Rudelius M, Bücklein V, Blumenerg V, Schmidt C, Karschnia P, Schöberl F, Dimitriadis K, Von Baumgarten L, Stemmler J, Weigert O, Dreyling M, Von Bergwelt-Baildon M, Subklewe M. Severe Candida glabrata pancolitis and fatal Aspergillus fumigatus pulmonary infection in the setting of bone marrow aplasia after CD19-directed CAR-T cell therapy- a case report. BMC Infect Dis. 2021b;21(1):121.

Sterner R, Sakemura R, Cox M, Yang N, Khadka R, Forsman C, Hansen M, Jin F, Ayssoufi K, Hefazi M, Schick K, Walters D, Chappell D, Ahmed O, Sahmoud t, Durrant C, Nevala W., Patnaik M, Pease L, Hedin K, Kay N, Johnson A, Kenderian S. CM-SF inhibition reduces CRS and neuroinflammation but enhances CAR-T cell function in xenografts. Blood. 2019;133(7):697-709.

Will Garner W, Samanta P, Haidar G. Invasive fungal infections after anti-CD19 chimeric antigen receptor-modified T-cell therapy: state of the evidence and future directions. J Fungi. 2021;7:156. 
Wudhikarn K, et al. DLBCL patients treated with CD19 CAR-T cells experience a high burden of organ toxicities but low nonrelapse mortality. Blood Adv. 2020;4(13):3024-33.

Yakoub-Agha I, Chabannon C, Bader P, Basak GW, Bonig H, Ciceri F, Corbacioglu S, Duarte RF, Einsele H, Hudecek M, Kersten MJ, Köhl U, Kuball J, Mielke S, Mohty M, Murray J, Nagler A, Robinson S, Saccardi R, Sanchez-Guijo F, Snowden JA, Srour M, Styczynski J, UrbanoIspizua A, Hayden PJ, Kröger N. Management of adults and children undergoing chimeric antigen receptor T-cell therapy: best practice recommendations of the European Society for Blood and Marrow Transplantation (EBMT) and the joint accreditation committee of ISCT and EBMT (JACIE). Haematologica. 2020;105(2):297-316.

Open Access This chapter is licensed under the terms of the Creative Commons Attribution 4.0 International License (http://creativecommons.org/licenses/by/4.0/), which permits use, sharing, adaptation, distribution and reproduction in any medium or format, as long as you give appropriate credit to the original author(s) and the source, provide a link to the Creative Commons license and indicate if changes were made.

The images or other third party material in this chapter are included in the chapter's Creative Commons license, unless indicated otherwise in a credit line to the material. If material is not included in the chapter's Creative Commons license and your intended use is not permitted by statutory regulation or exceeds the permitted use, you will need to obtain permission directly from the copyright holder.

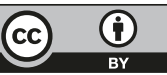

